\title{
O MERCOSUL: Reflexões sobre a Crise de seu Modelo de Integração e seu Relançamento
}

\author{
José Briceño Ruiz*
}

Resumo: Neste ensaio examina-se a atual crise do Mercado Comum do Sul (Mercosul). O argumento central do trabalho é que as atuais dificuldades do Mercosul respondem em grande parte à falta de cumprimento das metas estabelecidas no Tratado de Assunção. No entanto, este fator não é suficiente para explicar a crise, pois esta obedece também às deficiências do modelo de integração predominante no momento da criação do Mercosul.

Palavras-chave: Mercosul, Integração Regional, Modelo, Crise.

Abstract: This paper analyses the current crisis of the Common Market of the South (MERCOSUR). Hereby, it is argued that current Mercosur's difficulties are the result of the failure to achieve the aims established in the Treaty of Asuncion. Nonetheless, this factor is not enough to explain current crisis, because this latter is also closely related to the deficiencies of the integration model predominant at the moment when Mercosur was set up.

Keywords: Mercosur, Regional Integration, Model, Crisis.

\footnotetext{
* Professor-Pesquisador do Centro de Estudos de Fronteiras de Integração (CEFI) da Universidade dos Andes, Venezuela. E-mail: bricenoj@ula.ve. Recebido em 01/06/07 e aceito em 15/06/07.
} 
Num trabalho publicado em 1997, Aldo Ferrer descrevia o Mercosul como um processo que tinha em seu seio duas tendências ideológicas, uma que concebia esta iniciativa de integração como uma expressão do modelo neoliberal hegemônico naqueles dias na América Latina, e a outra que ainda lutava por defender algumas políticas estruturalistas que se tinham promovido desde meados da década de oitenta entre Argentina e Brasil.

Para Ferrer, se o Mercosul se enfocasse desde a perspectiva neoliberal do Consenso de Washington, seria uma área de preferências transitórias de intercâmbios na qual os mercados refletiriam, sem interferências do Estado, as forças centrípetas da geografia e a globalização mundial. Desde o enfoque da integração sustentável o Mercosul seria um projeto para criar uma zona preferente de comércio na qual os governos e os agentes sociais desenvolveriam estratégias e políticas ativas. O objetivo seria conseguir metas de desenvolvimento e equilíbrio intra-regional, inatingíveis somente com o jogo dos mercados.

Neste ensaio aceita-se este argumento de Ferrer. A partir dele se realiza uma reflexão sobre a evolução deste dilema na construção do Mercosul, examinando-se como isto afetou a construção de um modelo de integração diferente daquele proposto pelos Estados Unidos no Tratado de Livre Comércio da América do Norte (NAFTA), nos tratados bilaterais de livre comércio e na colapsada Área de Livre Comércio das Américas (ALCA).

Igualmente, neste trabalho analisa-se a forma como este dilema sobre o modelo de integração "mercosuliano" tem incidido na crise que este processo de integração atravessou depois da desvalorização do Real no Brasil em 1998. Esta crise levou a uma revisão do modelo de integração no seio do Mercosul, processo que foi acelerado com a ascensão ao poder na Argentina, no Brasil e no Uruguai, de governos com posiçôes econômicas críticas às políticas predominantes na década passada e que inspiraram o processo de integração regional.

\section{O nascimento e desenvolvimento do Mercosul: entre o Consenso de Washington e a integração sustentável}

Asseverar que o Mercosul se originou no Tratado de Assunção é historicamente incorreto. Este acordo constituiu uma nova etapa num 
processo de integração bilateral entre a Argentina e o Brasil que, a partir do segundo lustro da década dos anos oitenta, estava transformando o Cone Sul. A história remonta-se ao ano de 1985, quando no marco da democratizaçáo da região, os presidentes Raúl Alfonsín e José Sarney reúnem-se em Foz de Iguaçu e iniciam um esquema de integração bilateral que pode ser considerado como crucial no relançamento da integração latino americana, languescida após a crise da dívida em 1982. Em julho de 1986 subscreveu-se o Programa de Integração e Cooperação Econômica (PICE) entre a Argentina e o Brasil, que em seu início compreendeu 12 protocolos, posteriormente ampliados a 24.

OPICE não pode ser considerado como expressão de um modelo neoliberal de integração, pois as políticas econômicas dos governos de Sarney e Alfonsín distanciavam-se bastante da ortodoxia econômica (COSTA VAZ, 1993, p. 72). Estes governos promoveram programas heterodoxos como o Plano Austral e o Plano Cruzado, que tiveram um sucesso temporário em reverter o processo de inflação nos dois países, permitindo assim o desenvolvimento das iniciativas de integração bilateral. Para a Argentina, os protocolos subscritos eram parte de um conjunto de políticas de desenvolvimento industrial e de comércio exterior. Para o Brasil, ainda que o impacto da abertura argentina fosse muito menor, era importante estabelecer alianças estratégicas em setores como a energia nuclear, aeronáutica, indústria automotriz e alimentação (LAVAGNA, 1992, p. 82).

O PICE foi um programa baseado em princípios bastante diferentes aos que inspirariam a denominada integração aberta da década dos anos noventa. A graduação, flexibilidade, equilíbrio e simetria eram suas idéias reitoras, o que se materializou numa estratégia de integração paulatina por setores industriais cuja complementação dinâmica constituía o próprio núcleo do processo de integração (DE ALMEIDA, 2003, p. 77). Os acordos em matéria de complementação industrial assemelhavam-se mais ao velho projeto cepalista de uma integração gradual e seletiva que a "abertura" que propunha o neoliberalismo. Estes acordos eram parte de uma estratégia para procurar alternativas à ortodoxia que começava a se impor na regiáo (LAVAGNA, 1992, p. 96). Laredo e Angelone (1996, p. 27) afirmam que o PICE foi uma tentativa de transcender os moldes neoliberais com a 
finalidade de incrementar as margens de crescimento e autonomia regional, mediante a complementação industrial e a cooperação técnica, desarticulando paralelamente as hipóteses de conflito que prevaleceram entre a Argentina e o Brasil.

O PICE foi bem sucedido em seu início, especialmente em matéria comercial. Produziu-se um incremento substantivo no intercâmbio entre os dois países, revertendo a tendência para a queda que tinha ocorrido nos primeiros anos da década de oitenta. A Argentina, por exemplo, duplicou suas vendas para o Brasil e superou os Estados Unidos como o primeiro provedor desse país. Não se tratou somente de exportação de bens agrícolas, senão também de produtos industriais, dissipando assim os temores de uma especialização agrícola (DE ALMEIDA, 2003, p. 77). No entanto, o fracasso dos programas heterodoxos de Sarney e Alfonsín em meados de 1987, produziu uma crise interna que afetou o desenvolvimento do PICE. Em particular, os defases do tipo de mudança produziram movimentos cíclicos no comércio e uma política de aproveitar oportunidades em curto prazo que debilitou a capacidade de administrar a expansão do comércio e avançar o aprofundamento do processo.

$\mathrm{Na}$ sua última etapa, a integração bilateral experimentou mudanças qualitativas (STAHRINGER, 1992, p. 61). Em seus inícios, o núcleo era o protocolo 2 sobre bens de capital e a complementação industrial e tecnológica. Assim, no PICE existiam acordos bilaterais sobre seis das sete indústrias mais dinâmicas e, como assevera Lavagna (1994, p. 249), propunha-se um acordo sobre a criação de um marco de investimentos privados em empresas binacionais e um fundo de financiamento de investimento em projetos conjuntos nestas indústrias. Isto se abandonou na fase final do PICE, quando se privilegiou a expansão comercial. Ao assinar o Tratado de Integração, Cooperação e Desenvolvimento, em 1998, os governos da Argentina e do Brasil propuseram, como objetivo fundamental da integração bilateral, construir numa primeira etapa um espaço econômico em dez anos. No entanto, mantinham-se outras metas, como a harmonização de políticas aduaneiras, agrícola, comercial, industrial, de transporte e comunicações e a coordenação das políticas monetárias, fiscal e cambial.

Em 1990, os governos de Carlos Saúl Menem e Fernando Collor de Mello, 
ambos favoráveis às políticas do Consenso de Washington, subscreveram a Ata de Buenos Aires, cujo objetivo foi o estabelecimento de um mercado comum, prévio ao aperfeiçoamento de uma zona de livre comércio através de uma redução geral, linear e automática dos impostos e a criação de uma união aduaneira. Para Roberto Lavagna (1992, p. 97), esta nova metodologia de integração ainda que não violasse a lógica de 1986, alterava a seqüência temporária e, portanto o resultado. Em outras palavras, o projeto de integração sustentável, para utilizar a expressão de Ferrer, que se iniciou em Foz de Iguaçu em 1985, foi abandonado de forma gradual a partir de 1988 e em 1990 foi substituído pela lógica do Consenso de Washington. Quando se cria o Mercosul em 1991, não podia ser nada além da expressão da estratégia que se tinha já imposto na região. Por isso, Paulo Roberto da Almeida aponta que as linhas básicas do Tratado de Assunção foram estabelecidas no acordo argentino-brasileiro de 1988 e na Ata de Buenos Aires de 1990. A respeito, assevera que quase todos os mecanismos, instrumentos, órgãos e em especial os calendários de liberalização eram essencialmente os mesmos daqueles acordos. Igualmente assevera que o Tratado de Assunção não é nada mais que uma reprodução ipsi letteris dos mecanismos estabelecidos na Ata de Buenos Aires (DE ALMEIDA, 2003, p. 6).

O Tratado de Assunção incorporou em quase a sua totalidade as recomendações do Consenso de Washington. Seus objetivos eram a inserção competitiva dos países nos mercados mundiais, a promoção de economias de escala e a ampliação do comércio e os investimentos. Para isso, se estabeleciam como instrumentos: 1) um programa de liberalização comercial linear, progressiva e automática, livre circulação de bens, serviços e fatores, 2) a coordenação das políticas macroeconômicas, 3) o estabelecimento de uma tarefa externa comum, 4) a adoção de acordos setoriais e 5) a regulação de um regime geral de origem, cláusulas de salvaguarda e soluçâo de controvérsias.

No entanto, a diferença entre outras iniciativas de integração latinoamericanas e o viés neoliberal de algumas políticas do Mercosul, estiveram justapostos a algumas formas de intervenção pública. Este híbrido respondeu menos às recomendaçóes econômicas da receita do Consenso de Washington e mais aos interesses estratégicos do hegemon do processo regional: o Brasil. Para Monica Hirst (1994, p. 316-317), em diferentes segmentos do 
Estado e da sociedade brasileira, predominava uma visão que reclamava a construção de um novo projeto nacional, ainda que não existisse um consenso sobre o conteúdo do mesmo. Náo obstante, ainda que se reconhecesse a obsolescência do modelo econômico vigente em meados dos anos oitenta, ao mesmo tempo propunha-se a necessidade de manter uma estrutura industrial complexa e diversificada. Mariana Vasquez (1998) coincide com este enfoque ao asseverar que para o Brasil este projeto excluiu desmontar seu plano de desenvolvimento nacional. Portanto, Brasília procurou evitar que o país e o Mercosul fossem submetidos totalmente à lógica do Consenso de Washington. O Brasil conservou as linhas centrais de seu projeto nacional, pois as reformas econômicas que promoveu não significaram o abandono de mecanismos de regulação, senão a vontade de escolher os meios mais adequados para implementar um modelo industrial que permitisse a participação das empresas brasileiras no novo contexto econômico internacional (VÁSQUEZ, 1998, p. 42).

Apesar de aplicar um programa de ajuste, inclusive o governo de Fernando Collor de Mello, manteve políticas intervencionistas de fomento e políticas setoriais de apoio ao setor privado como, por exemplo, os empréstimos do Banco Nacional de Desenvolvimento ao setor de bens de capital, as políticas setoriais em diversas manufaturas e o programa de desenvolvimento científico tecnológico. Collor também concedeu linhas de créditos para apoiar os empresários que ingressassem em programas de modernização tecnológica. Diferentemente do vasto programa de privatizaçóes de Menen, Collor anunciou a privatização de somente um pequeno grupo de empresas, que incluía dez no setor petroquímico no lapso de três anos. O Brasil também criou um Fundo Nacional de Estatização e decidiu a colocação compulsória de certificados de privatização entre as entidades financeiras nacionais para investir em empresas que pudessem ser privatizadas. Do mesmo modo, a Constituição brasileira exclui ou restringe a presença de investidores estrangeiros na exploração do petróleo e outros setores estratégicos (STAHRINGER, 1992, p. 62).

Tudo isto evidencia que inclusive o governo brasileiro mais comprometido com as idéias neoliberais (Collor de Mello) não pôde deixar de aplicar medidas intervencionistas. Isto obedecia às pressóes de fortes grupos 
econômicos brasileiros que ainda demandavam proteção durante o processo de formação de preferências nacionais no processo de elaboração da política de integração. Inegavelmente, isso se refletiu no Tratado de Assunção, quando as preferências nacionais foram objeto de um processo de negociação inter-governamental, que resultou num texto final do acordo que incluiu políticas de abertura e liberalização comercial de forte inspiração neoliberal misturadas com medidas de comércio administrado no setor automotriz.

Em conseqüência, o argumento do Mercosul como sinônimo de neoliberalismo é incorreto. É indiscutível que o Tratado de Assunção teve sérias deficiências que afetaram seu posterior desenvolvimento, como a existência de um déficit democrático ou de uma instituição bastante precária. No entanto, isto se relaciona mais com a dimensão política do processo do que com o modelo econômico. Também é verdadeiro que no Mercosul, especialmente os elementos vinculados ao enfoque do Consenso de Washington, tiveram grande importância durante o período de transição e até 1998, mas nestes anos nunca se considerou, por exemplo, derrogar a política automotriz. Em outras palavras, o Mercosul não foi só mercado. A tradição intervencionista brasileira não o permitiu, apesar de Collor e de Menem. Em vez disso, foi um híbrido no qual ademais a intervenção não sempre se baseou na busca da idéia de solidariedade, o que explica seu pobre desempenho no tratamento das assimetrias ou a ausência de uma agenda social.

Além disso, o Mercosul é resultado de uma aliança entre a Argentina e o Brasil, na qual este último país teve uma forte liderança. Autores como Mario Carranza (2004, p. 328), assinalam que o interesse do Brasil no grupo regional se explica mais por razóes estratégicas (fortalecer seu poder vis-à-vis Estados Unidos) que comerciais, e neste aspecto a aliança com a Argentina teve um papel fundamental. Andrés Malamud (2005, p. 425) coincide com este enfoque quando assevera que o Mercosul foi um dos componentes mais importantes da política exterior brasileira dos anos noventa, que foi ampliada desde meados dessa década ao tentar expandir o processo de integraçáo ao resto de América do Sul. Esta dimensão estratégica é também uma variável fundamental para entender o modelo de integração do Mercosul. 


\section{A crise do Mercosul}

O MERCOSUL foi criado num momento no qual existia um consenso entre os governos sobre a adoção de uma política de livre mercado e a liberalização comercial. Este consenso, não obstante, debilitou-se com a crise do Real em 1998 e desapareceu com o default argentino de 2001. Nos anos de consenso ideológico produziu-se um incremento significativo no intercâmbio comercial, como foi amplamente resenhado em diversos estudos. Assim, as exportaçóes intra-Mercosul aumentaram de 9\% em 1990 a $25 \%$ em 1998, ao mesmo tempo em que cerca de $95 \%$ do intercâmbio intra-regional estava livre de tarefas para fins da década dos anos noventa (BIDELEUX, 2005, p. 181). Mais importante ainda que este crescimento do comércio era a qualidade dos bens negociados, pois diversos estudos evidenciam que durante esses anos se produziu um incremento substantivo do intercâmbio de um conjunto de bens mais intensivos em tecnologia que não são objeto de comércio com o resto do mundo, apoiando assim um padrão de especialização intra-industrial (KOSACOFF, 2006, p. 87).

Do mesmo modo, o investimento estrangeiro cresceu de forma contínua durante a década dos anos noventa, permitindo ao Mercosul triplicar a participação nos fluxos totais a nível mundial - de 2\% em 1990-1993 a quase 6\% em 1997-1999 - (KOSACOFF, 2006, p. 87). No entanto, foi a crise que afetou a economia brasileira no final de 1998, que culminou com a desvalorização do Real no início de 1999, o que produziu um deterioro no cenário regional, sendo o detonante de um período de crise no Mercosul, a qual nâo tem sido superada. $\mathrm{O}$ efeito imediato da desvalorização do real foi a alteraçáo da competitividade no interior do bloco comercial, afetando de forma significativa os ganhos na regionalização do comércio atingidos no período de transição. Esta situação agravou-se em 2001 devido a crise econômica argentina. Durante o primeiro semestre desse ano, Buenos Aires decidiu reduzir unilateralmente a zero os impostos para os bens de capital e incrementá-los para os bens de consumo ao máximo permitido pela Organização Mundial do Comércio (OMC - 35\%). Meses mais tarde, Domingo Cavallo, designado Ministro de Finanças por Fernando de la Rúa, anunciaria as restriçóes aos depósitos bancários, o que se conheceria depois como o "corralito", medida que aceleraria a crise que conduziria ao 
mesmo abandono da presidência por de la Rúa em dezembro de 2001. O impacto desta crise sobre o Mercosul foi demolidor. Tão só a eliminação da convertibilidade produziu uma desvalorização técnica de $29 \%$ e outra real de mais de $70 \%$ que favoreceu a indústria argentina (BERNAL-MEZA, 2002, p. 11). Isto ocasionou uma diminuição do comércio intra-regional. As importaçóes argentinas provenientes do Mercosul atingiram 25.280,49 milhôes de dólares no ano 2000. Durante o ano da crise caíram a 21.001,44, para sofrer uma abrupta queda em 2002, quando chegaram a 8.991,00 milhóes de dólares (LERMAN ALPERSTEIN, 2005, p. 367).

O ano 2003 esteve acompanhado por mudanças de governos na Argentina e no Brasil, desde então sob as conduçóes de Néstor Kirchner e Luiz Inácio Lula da Silva. Ambos os líderes chegaram ao poder com um discurso crítico ao modelo econômico aplicado na região desde a década dos anos noventa. Neste contexto, os dois presidentes decidiram promover uma Aliança Estratégica, expressão da qual foi o Consenso de Buenos Aires, subscrito por Lula e Kirchner no dia 16 de outubro de 2003. Neste, os Chefes de Estado se comprometeram a: a) incrementar o acordo e a cooperaçáo política para impulsionar o projeto regional; b) incluir uma agenda social no MERCOSUL, c) implementar a união aduaneira e conformar o mercado comum, d) fortalecer a coordenação nas negociações internacionais e; e) promover a cooperaçáo para garantir um espaço de segurança comum e de vigilância dos ilícitos na região (BIZZOZERO, 2003, p. 134).

Posteriormente, na cúpula de Assunção realizada em junho de 2003, aprovou-se o Programa para a Consolidação da União Aduaneira e para o Lançamento do Mercado Comum, objetivo 2006. Este programa tem quatro eixos: a) um Programa Político, Social e Cultural; b) um Programa da Uniāo Aduaneira; c) um Programa de Base para o Mercado Comum; e d) um Programa da Nova Integração.

No entanto, no meio destes esforços para reestruturar o Mercosul, este processo experimentou uma nova crise derivada da "rebelião dos sócios de menor tamanho", entenda-se Paraguai e Uruguai. Nestes dois países é cada vez maior a percepçáo de que o Mercosul foi um processo assimétrico que favoreceu fundamentalmente ao Brasil e à Argentina. Este mal-estar agravouse devido ao confronto entre Argentina e Uruguai pela instalação de uma 
fábrica de celulose na cidade de Fray Bentos. Segundo Buenos Aires, esta indústria teria graves conseqüências ambientais e violaria o regime comum de administração do Rio Uruguai (BRICEÑO RUIZ, 2006).

$\mathrm{O}$ interesse uruguaio em subscrever um tratado de livre comércio (TLC) com os Estados Unidos, o qual seria uma violação das normas do Mercosul, acentuou ainda mais a crise. Ainda que a proposta do TLC não se tenha materializado, Montevidéu já subscreveu em janeiro de 2007 um acordo marco de comércio e investimento com os Estados Unidos (conhecido como TIFA). Muitos temem que este seja o primeiro passo para o TLC, especialmente pelos temas que se incluem no anexo deste acordo, que são os mesmos que foram parte da negociação da ALCA e os TLC (propriedade intelectual, investimentos, serviços, compras governamentais). Este cenário pode se agravar se o Paraguai decide subscrever um TIFA com os Estados Unidos, aceitando a oferta recentemente feita pelo Secretário de Estado Adjunto para Assuntos do Hemisfério Ocidental, Thomas Shannon, em abril de 2007 (AGÊNCIA REUTERS, 27/04/2007).

\section{A crise e o debate sobre o novo modelo}

A crise que vive o Mercosul desde fins da década dos anos noventa obedece em grande parte ao dilema que existe no interior deste processo em torno do modelo de integração. Como se analisa na seção prévia, no período de hegemonia neoliberal o Mercosul avançou bastante em suas metas e foi capaz de estabelecer com sucesso o delicado equilíbrio entre as medidas liberais e intervencionistas. No entanto, após a crise do Real o deterioro do MERCOSUL foi evidente e os equilíbrios foram cada vez mais difíceis de se atingir.

Em primeiro lugar, é necessário assinalar que o Mercosul tinha uma evidente dimensão comercial expressa na liberalização das trocas, no estabelecimento de uma tarifa externa comum e na meta deliberalizar os fatores de produção para atingir um mercado comum. No entanto, diferentemente do modelo de integração profunda como a ALCA, no Mercosul a regulação do comércio de serviços e dos temas relacionados com o comércio, como a propriedade intelectual, as compras governamentais ou os investimentos, não se realizavam de acordo com os princípios liberais. Assim por exemplo, 
no MERCOSUL se rejeitavam a liberalização indiscriminada nas áreas das telecomunicaçóes, os serviços financeiros e as compras governamentais. Inclusive, o Protocolo de Colônia sobre Investimentos permitia aos Estados membros reservarem aos cidadãos do Mercosul a propriedade dos meios de comunicação, a participação em atividades de intermediação financeira e as compras governamentais (INFORME LATINOAMERICANO, 1997, p. 364). Certamente, este protocolo nunca foi ratificado pelas legislaturas nacionais, mas sua redação em termos tão diferentes da ALCA manifesta o desejo de optar por um modelo diferente ao promovido pelos Estados Unidos.

Apesar desta apreensão com relação à implantação de uma integração profunda, um fator que permite distinguir o Mercosul da ALCA, o grupo regional tem ainda uma série de insuficiências e pontos fracos. Victor Sukup (2005, p. 196) assevera que quatro das deficiências que confluíram no estancamento do Mercosul são as seguintes: a) a ideologia neoliberal predominante na Argentina, que impediu o desenvolvimento de qualquer estratégia industrial e de uma política exterior compatível com um projeto de integração regional, sustentado numa estratégia com forte conteúdo endógeno; b) a preferência por setores industriais tendentes a distorcer ainda mais o perfil da demanda ao privilegiar o consumo das capas de maiores rendas da sociedade, como se tem evidenciado pela prioridade que se deu ao setor automotriz; c) a comum sobrevalorização das moedas, e d) a ausência de uma estrutura institucional eficiente.

A questão industrial é evidentemente um dos aspectos que deve ser considerado na discussão de um novo modelo de integração para o Mercosul. Certamente, é necessário superar uma estratégia industrial só concentrada na indústria automotriz. É discutível o argumento de Sukup (2005) que a preferência por este setor gere uma distorção na demanda e só favoreça aos setores de maiores rendas, mas é indiscutível que o Mercosul precise de uma política industrial regional. Isto supóe resgatar a tradição prebischiana de converter a integração regional num mecanismo para a transformaçáo produtiva da região. Neste sentido, o fim da era neoliberal na Argentina abriu um espaço para promover uma política industrial do Mercosul, um primeiro exemplo do qual foi a adoção do mecanismo de adaptaçáo competitiva 
(MAC), que permitiu a existência de intercâmbios comerciais entre a Argentina e o Brasil com salvaguardas, cotas e licenças não automáticas que impediam o fim da industrialização na Argentina (GARCÍA DELGADO, CHOJO, 2006, p. 128).

A adoção do MAC é apenas um primeiro passo, que tem ademais um âmbito bilateral, pois Paraguai e Uruguai não são partes deste mecanismo. Inclusive poderia conceber-se como um mecanismo provisório, que deve se substituir por uma verdadeira política industrial, na qual predomine uma visão estratégica que permita investimentos conjuntos de empresas e correntes produtivas que, por sua vez, facilitem a posteriori ascender com a escala adequada aos mercados internacionais. Este aspecto é fundamental, pois o papel de um empresariado nacional empreendedor é vital para o sucesso do Mercosul. Em conseqüência, este processo de integração deve promover a formação de correntes de valor agregado, alentando um jogo sumo positivo para promover a complementação, a incorporação tecnológica e a capacidade exportadora conjunta, considerando o Mercosul como um mercado interno ampliado (GARCÍA DELGADO, CHOJO, 2006, p. 129).

Outra das carências do Mercosul foi a incapacidade de atingir uma coordenação das políticas econômicas, um dos objetivos propostos no Tratado de Assunção. Esta foi uma das contradições maiores do desenvolvimento do Mercosul, já que depois do aparente consenso em torno das políticas neoliberais, os dois sócios maiores (Argentina e Brasil) foram incapazes de se coordenar em aspectos como a política industrial, monetária e cambial. Em torno da política industrial é bem conhecido o abandono de qualquer modalidade de intervenção nesta matéria por parte da administração Menem, enquanto o Brasil, inclusive nos anos de Collor, sempre manteve formas de apoio à indústria nacional. No caso da política cambial, a permanência durante quase uma década do mecanismo de caixa conversão na Argentina, impediu uma coordenação nesta matéria com Brasília, que apoiou a flutuação de sua unidade monetária. A crise argentina de 2001 e o fim da caixa de conversão criaram as condiçóes para promover uma maior coordenação de políticas. Para que esta coordenação possa ser atingida é necessária a definição do modelo de integração que se deseja fomentar: trata-se de promover um MERCOSUL centrado na liberalização tarifária e a unificação de mercados? Ou a unificação das economias? 
Outro problema crucial do Mercosul atual é a ausência de mecanismos para tratar as assimetrias existentes neste processo de integração. Este problema gerou a percepção, especialmente nos dois sócios de menor tamanho, de que os beneficiários do processo de integração foram Argentina e, especialmente, Brasil. No Paraguai e Uruguai reclama-se por ter pago os custos de participar na união aduaneira sem obter maiores vantagens, devendo padecer ademais as causas externas negativas da crise do Real e o default argentino, sem nem sequer existir uma instituição eficiente através da qual canalizar suas demandas. Um experto paraguaio afirma que no seu país percebe-se que o Mercosul conduziu os países pequenos a diminuir seu comércio com o mundo sem compensações (RODRÍGUEZ, 2001, p. 368). A criação de mecanismos para tratar as assimetrias que se possam gerar da integração entre sócios com diversos níveis de desenvolvimento econômico relativo é, porém, um reto para o Mercosul.

O tratamento do problema das assimetrias supóe um esforço conjunto para criar infra-estrutura regional, rodoviária, energética e telecomunicação que permita homogeneizar as condiçóes econômicas e sociais, agindo como motores neo-keynesianos de emprego regional e impactando em áreas e populaçóes que são hoje marginais nas políticas nacionais (GARCÍA DELGADO, CHOJO, 2006, p. 129).

A criação do Fundo de Compensação Econômica do Mercosul (FOCEM) em 2004 propóe-se contribuir a resolver as assimetrias existentes. Trata-se um pouco de imitar os Fundos Regionais da União Européia, que com a contribuição majoritária da Alemanha e da França fizeram o orçamento comunitário e foram chaves na redução das disparidades no interior do espaço integrado. Pelas teorias da Política Econômica Internacional, a contribuição majoritária da França e Alemanha a estes fundos constitui uma das cargas que têm que levar devido a seu papel de hegemon no seio da União Européia, carga que é recompensada mediante um sistema regional estável e em progresso (BRICEÑO RUIZ, 2006). O problema do Mercosul é que, por um lado, diferente da UE, não tem um orçamento próprio e as políticas comuns que se aprovam devem ser financiadas por cada um dos Estados membros (MEDEIROS, 2000, p. 304). Por isso o FOCEM, aprovado no ano 2004, tem um capital de início bastante limitado e será formado 
com contribuiçôes de cada país membro. Ainda que estas contribuiçóes distribuam-se em proporção inversa ao tamanho das economias, o qual introduz um elemento de equidade, seu monto parece limitado. Por outro lado, o outro problema do Mercosul é que o Estado que pode desempenhar o papel de hegemon é Brasil, um país que se negou a assumir os custos de sua condição de líder do processo. No caso de uma política de redistribuição no Mercosul, é necessário não obstante reconhecer que o Brasil é um país com enormes assimetrias internas, especialmente entre o sul industrial e a regiāo nordeste. Em conseqüência, para qualquer governo brasileiro será politicamente complexo justificar o envio de recursos para resolver problemas de regióes atrasadas de outros países, sem resolver primeiro os seus.

Uma das maiores limitaçóes do Mercosul como modelo de integração é a ausência de uma agenda social. E isto é lógico de compreender, já que as forças sociais que participaram no processo de formação de preferências foram os empresários, especialmente aqueles com uma orientação internacional, e os Estados nação. Em conseqüência, no Tratado de Assunção só se propuseram objetivos comerciais, estando ausente qualquer objetivo de tipo social. Isto se expressou numa sorte de falta de dolentes do MERCOSUL no seio dos movimentos sociais e organizações não governamentais, que percebem ao grupo regional só como um esquema que favorece aos interesses dos setores produtivos. A ampliação da base social de apoio do MERCOSUL supõe a inclusão de uma agenda social neste esquema de integração. Não se trata, como acertadamente assinala Andrés Malamud (2005, p. 423), de dar ao Mercosul um "status épico" como instrumento preferido para objetivos sociais mais que meramente econômicos. Certamente não é o caso, pois a resolução dos problemas da pobreza ou da desigualdade não se dará de forma exclusiva pela integração regional, pois se tratam de dificuldades estruturais que requerem um grande esforço no interior de cada país. A integração regional, no entanto, pode fazer uma grande contribuição em sua solução. Neste sentido, não se deve esquecer que o produtivo está vinculado com o social. A defesa da indústria é a defesa do emprego e da distribuição da riqueza, pelo que é necessária uma maior coordenação da política em matéria de emprego, a melhora de sua qualidade e a diminuição da vulnerabilidade na construção da regiấo. Trata-se então de desenvolver políticas pró-ativas, 
orientadas à produção e ao emprego, no qual este último seja fomentado mediante investimentos em infra-estrutura, produção, tecnologia e recursos humanos (GARCÍA DELGADO, CHOJO, 2006, p. 129)

Desde a ascensão ao poder de Luiz Ignácio Lula da Silva no Brasil e de Néstor Kirchner na Argentina, estabeleceram-se medidas na direção de revisar o modelo hegemônico na década dos anos noventa. Reconhecendo que o Mercosul tem uma agenda comercial ainda inconclusa que não se deve abandonar, identificou-se a existência de novos temas que devem ser parte do processo de integração. Assim por exemplo, no Programa para a Consolidação da União Aduaneira, aprovado na Cúpula de Assunção de 2003, estabeleceuse uma agenda na qual os velhos temas comerciais agora são parte de uma agenda maior. A agenda aprovada na capital paraguaia compreende quatro programas. O Programa Político, Social e Cultural propóe-se a outorgar uma maior preeminência ao Foro Consultivo Econômico e Social e à Comissão Parlamentar Conjunta do Mercosul, de maneira a ampliar a participação dos atores não governamentais e do Congresso. O Programa da União Aduaneira, por sua vez, inclui uma série de iniciativas para consolidar a união aduaneira, estabelecendo como data limite o ano 2006 para concluir o processo de convergência aduaneira. O Programa de Base para o Mercado Comum propóe cronogramas para a ratificação do Protocolo sobre Comércio de Serviços, conclusão do Acordo sobre Compras Governamentais e ratificação do Acordo sobre Residência de Nacionais, aprovado pelos Ministros do Interior durante o ano 2002. O Programa reitera a necessidade de examinar a conveniência e os requisitos para o estabelecimento de um mercado regional de capitais. Finalmente, o Programa da Nova Integração estabelece iniciativas relacionadas com a educação na região, como o reconhecimento mútuo de diplomas (não só para os efeitos acadêmicos), o desenvolvimento de programas de cooperação em ciência, tecnologia e integração produtiva, e a integração física (BOUZAS, 2003).

No entanto, existem riscos ante esta nova realidade. O primeiro deles é o de se criar uma nova série de objetivos sem se ter cumprido os ainda inconclusos, ou ao menos sem fazer um maior esforço para cumpri-los. Neste sentido, num recente artigo, Paulo Roberto de Almeida (2007) afirma que o MERCOSUL foi levado a efetuar uma "fuga para frente", o que se explica 
pela promoção de um número cada vez maior de iniciativas para compensar as tarefas não cumpridas em sua agenda corrente. De Almeida critica a criação de novos órgãos acessórios ou de redistribuiçãao e a promoção de iniciativas setoriais nos campos político, social e cultural, sem coordenação entre eles. Esta dura crítica de Almeida, ainda que expresse a opinião de um setor acadêmico que concebe ao MERCOSUL só como um mecanismo de liberalização econômica (ALMEIDA, 2007, p.1), não obstante merece ser considerada porque recorda uma realidade do MERCOSUL: neste processo de integração existe uma agenda comercial inacabada. Assim, por exemplo, o Mercosul tem tarefas como o aperfeiçoamento da União Aduaneira (ainda imperfeita depois de uma década) e em particular a tarifa externa comum, a eliminação das exceções à zona de livre comércio e um maior esforço na coordenação das políticas econômicas. Estas metas devem cumprir-se e neste aspecto nos distanciamos de Almeida, pois isto não é obstáculo para avançar ao mesmo tempo num Mercosul produtivo e social, porque não são necessariamente excludentes.

Existe um segundo risco, derivado do fato que o Mercosul possa ter um destino similar aos outros processos de integração latino-americanos, como o Mercado Comum Centro-Americano (MCCA) no início da década dos anos setenta e o antigo Pacto Andino no final dessa mesma década e meados dos anos oitenta. Frente à suas insuficiências estas duas iniciativas de integração propuseram metas mais ambiciosas, que não puderam cumprir e depois se produziu uma estagnação do processo. Na teoria da integração isto se conhece, especialmente na escola neo-funcionalista, como processos de "spill back" e "spill around". Explicando a crise do MCCA após o estalido da Guerra do Futebol entre El Salvador e Honduras, Phillipe Schmitter (1970) observou o desenvolvimento de um processo de "spill back", isto é, uma regressão na integração regional pela qual as instâncias decisórias perderiam a capacidade que teriam adquirido para agir em determinados setores. Isto por sua vez provocaria um "spill around" ou um "efeito de encapsulamento", descrito por Schmitter como uma mistura dos sintomas de desborde (spill over) e regressão (spill back) caracterizada pela proliferação de esforços independentes em matéria de coordenação regional, mas sem chegar a delegar a autoridade num ente coletivo único. Isto produziria uma regionalização de novos 
campos de ação e o incremento das transaçóes mútuas, porém sem gerar uma redefinição funcional das normas. Em outros termos, não se evoluiu para um processo político supranacional, nem também não se criou um sentido novo ou mais arraigado de lealdade comunitária (SCHMITTER, 1970).

Não se trata de assumir uma posição pessimista, mas no Mercosul pode-se observar um complexo cenário regional, no qual por um lado trata-se de modificar o viés neoliberal e comercial que caracterizou o bloco regional, mediante a introdução de certas políticas de redistribuição ou favorecendo formas embrionárias de integração produtiva. Apesar disso, não se avança e inclusive por momentos se retrocede nos temas pendentes da agenda e também não se estabelece uma instituição mais forte que seja capaz de manejar de forma bem-sucedida as causas externas negativas que geram a crescente interdependência. Isto é fundamental para examinar as possibilidades de sucesso de uma revisão do modelo de integração puramente centrado no comércio por um outro que também inclua metas produtivas e sociais. Para que este processo tenha sucesso é necessário um compromisso político a respeito dos atores regionais, mas especialmente se precisa que os atores atinjam um mínimo denominador comum sobre a agenda, estrutura institucional e políticas comuns. No entanto, as diferenças atualmente existentes entre vários sócios propóem interrogantes, ainda que não necessariamente insuperáveis, a este respeito.

\section{Conclusões}

O Mercosul atravessa na atualidade o enorme desafio de evitar que se consolide o retrocesso da integração regional (spill back em termos neofuncionalistas) ou que seja substituído por uma falsa percepção de esforços de relançamento da integração mediante a criação de novas metas sem cumprir metas prévias e sem criar instituiçôes que permitam cristalizar os novos objetivos regionais. Se isto não se realiza, a erosão da credibilidade do Mercosul como processo de integração continuará. No entanto, para sair desta crise, é necessário propor a pergunta para que deve servir o Mercosul.

Autores como Roberto Bouzas (2003, p. 36) têm respondido. Para ele, o Mercosul deve ser um instrumento para melhorar o bem-estar através de um maior ritmo de crescimento econômico e de uma melhor inserção da região 
na economia mundial. Neste sentido, Bouzas (2003) propóe uma agenda que deve prestar atenção a três áreas prioritárias. Em primeiro lugar, deveria-se melhorar as condiçóes de acesso aos mercados, incluindo o estabelecimento de mecanismos para enfrentar situaçóes especiais. Em segundo lugar, terminar de definir a política comercial frente a terceiros, seja mantendo a meta de criar uma união aduaneira ou optando por uma opção estratégica. Finalmente, estabelecer-se mecanismos de formulação e aplicação de regras que sejam mais efetivos (BOUZAS, 2003, p. 238-240).

Esta proposta de Bouzas (2003) pode-se resumir na frase "cumprir os compromissos contraídos". Efetivamente, no Tratado de Assunção estabeleceram-se uma série de objetivos que ainda não se tem atingido de forma cabal. É verdade que se estabeleceu uma zona de livre comércio, com escassos regimes de exceção, mas a ausência de mecanismos para tratar situações de exceção (como a crise do Real ou o default argentino) provocou sérios retrocessos no regime de livre comércio. Exemplo disto foi a "Guerra de medidas unilaterais de salvaguarda” que se produziu em 1999 após a desvalorização do real. Igualmente, o Mercosul não pode pretender manter permanentemente seu particular status de "união aduaneira imperfeita", pois isto não só tem incidência nas relaçóes externas do grupo, mas também na estratégia produtiva da regiâo. Igualmente, o déficit institucional é um problema estrutural que limitou sua capacidade de superar as crises do processo de integração. Em conseqüência, não é difícil coincidir com Bouzas o quanto a saída da crise do MERCOSUL exige tomar decisóes sobre estes temas, que este autor descreve como "prosaicos" (BOUZAS, 2003, p. 241).

No entanto, o cumprimento desta agenda não será suficiente para garantir a saída da crise do Mercosul. De novo é válida a pergunta para que serve o MERCOSUL, e existem respostas muito diferentes àquela de Bouzas (MALAMUD, 2006, p. 5-6). Uma delas é que o MERCOSUL tem dois déficits fundamentais. O primeiro é a ausência de um mecanismo de integração produtiva e o segundo é o déficit da equidade. Isto é compreensível caso se tome em conta que o Tratado de Assunção se assinou na época de hegemonia do Consenso de Washington, que era pouco favorável a formas de intervenção pública na economia.

Estes dois déficits são tão responsáveis pela crise do Mercosul como o 
não-cumprimento dos objetivos "prosaicos" do Tratado de Assunção. Boa parte dos conflitos recorrentes entre a Argentina e o Brasil nos últimos anos é resultado da ausência de ao menos uma coordenação da política industrial no seio do Mercosul. Em vez disso, a Argentina optou por uma política "anti-industrial” (FERRER, 2006, p. 14), enquanto o Brasil teve uma política mais pró-ativa. Isto gerou uma modificação da estrutura do comércio bilateral favorável ao Brasil que pôde incorporar um maior valor agregado e tecnologia em suas exportaçóes. Quando em 1999 o Real é desvalorizado ou quando o novo governo de Kichner tentou promover um processo de re-industrialização, a ausência de uma política de integração industrial no Mercosul emerge com toda crueza.

A outra grande crise que atravessa o Mercosul, como o é o reclamo de Uruguai e Paraguai de uma mais justa distribuição dos benefícios do processo de integração, também não se relaciona com o cumprimento das metas do Tratado de Assunção, mas é resultado de uma das limitações mais notórias do modelo de integração que se adotou na década dos anos noventa: a ausência de mecanismos para tratar as assimetrias entre países e entre as regióes subnacionais dos membros do processo de integração.

Em conseqüência, a crise do Mercosul responde a uma dupla vertente. Por um lado, o não-cumprimento de metas comerciais e de coordenação de políticas que deveriam ter-se aplicado no final da década passada, e por outro lado, a necessidade de revisar o modelo de integração para avançar "além do comércio”. Neste sentido, apesar de seus limitados avanços, o Consenso de Buenos Aires e o Programa para a Consolidação da União Aduaneira e para o Lançamento do Mercado Comum, incluem medidas adequadas para revisar o modelo de integração e relançar o Mercosul. No entanto, e este é um aspecto fundamental deste processo, se não existe um compromisso político pelos atores da região, estes esforços, em vez de conduzirem a um relançamento do Mercosul, poderiam levar a processos de "spill back" e "spill around", repetindo assim a história de outros processos de integração latinoamericanos em décadas passadas. 


\section{Referências Bibliográficas}

AGENCIA EFE. 10 maio. 2006.

AGENCIA REUTERS. 27 abril. 2007.

BERNAL-MEZA, Raul. La crisis argentina: su impacto en las relaciones bilaterales argentino-brasileñas y sobre el MERCOSUR. Cadernos PROLAM/USP, São Paulo, Universidade de São Paulo, n. 2, 2002.

BIDELEUX, Robert. El MERCOSUR y la Unión Europea: ¿Cómo se comparan dos modelos de integración regional. In: BERNAL-MEZA, Raúl; KUMAR SAHA, Suranit (Edit.). Economía mundial y desarrollo regional. Buenos Aires: Nuevohacer Grupo Editor Latinoamericano, 2005, p. 163-183.

BIZZOZERO, Lincoln. Los cambios de gobierno en Argentina y Brasil y la conformación de una agenda del Mercosur ¿¿Hacia una nueva cartografía sudamericana/interamericana. Nueva Sociedad, n. 186, julio./ago., p. 128-142, 2003.

BOUZAS, Roberto. ¿Puede sobrevivir el MERCOSUR? Perfiles Latinoamericanos, México, FLACSO, n. 23, p. 231-242, 2003.

BOUZAS, Roberto; DA MOTTA VEIGA, Pedro. La reunión cumbre de Asunción. ¿Hacia donde va el MERCOSUR? Serie MERCOSUR, n. 21, 12 ago. 2003.

BRICEÑO RUIZ, José. El MERCOSUR de cinco estrellas: reflexiones sobre los beneficios y costos del ingreso de Venezuela. In: LLAIRO, Monserrat; BRICEÑO RUIZ, José; BIZZOZERO, Lincoln. Venezuela en el MERCOSUR. Tres miradas, tres interpretaciones. Buenos Aires: CEINALDI, Universidad de Buenos Aires, 2006, p. 55-100.

CARRANZA, Mario. MERCOSUR and the end Game of the FTAA negotiations: Challenges and Prospects after the Argentine Crisis. Third Word Quarterly, v. 25, n. 2, p. 319-337, 2004.

COSTA VAZ, Alcides. Neoliberalismo na América Latina: impacto e perspectivas para o regionalismo econômico. Revista Brasileira de Política Internacional, Nova Serie, Brasília, v. 36, n. 2, p. 67-79, 1993. 
DE ALMEIDA, Paulo Roberto. O Mercosul no contexto regional $e$ internacional. São Paulo: Edicôes Aduaneiras, 2003.

DE ALMEIDA, Paulo Roberto. Sete teses impertinentes sobre o MERCOSUL. 2007. Mimeo.

FERRER, Aldo. Integração regional e desenvolvimento na América do Sul. Conferência organizada pelo Fórum de Integração Regional. Observatório Político Sul-Americano, Instituto Universitário de Pesquisas de Rio de Janeiro (IUPERJ), 28 abril. 2006.

GARCÍA DELGADO, Daniel; CHOJO Martin. Desarrollo e integración regional. Hacia un modelo productivo social. Buenos Aires: FLACSO, Ediciones CICCUS, 2006, p. 119-138.

HIRST, Mônica. La participación de Brasil en el proceso del MERCOSUR: evaluando costos y beneficios. In: ROJAS ARAVENA, Francisco; C. SMITH, William (Edit.). El Cono Sur las transformaciones globales. Santiago: FLACSO, North South Center, CLADDE, 1994, p. 315-331.

INFORME LATINOAMERICANO. 5 ago. 1997.

KOSACOFF, Bernando. Ventajas competitivas y la integración de Argentina en el MERCOSUR. In: ALBERTI, Giorgio; LLENDERROZAS, Elsa; PINTO, Julio (Edit.). Instituciones, democracia e integración regional en el MERCOSUR. Buenos Aires: Prometeo Libros, Bononiae Libris, 2006, p. 73-98.

LAREDO, Iris Mabel; ANGELONE, Juan Pablo. El neoliberalismo como sustento teórico del proceso de integración en el MERCOSUR. In: LAREDO, Iris Mabel (Comp.). Estado, mercado y sociedad en el MERCOSUR. Pautas para su viabilización. Rosario: Universidad Nacional de Rosario, 1996, p. $15-56$.

LAVAGNA, Roberto. Integración Argentina Brasil. Origen, resultados y perspectivas. In: BEKERMAN, Marta (Comp.). MERCOSUR: la oportunidad y el desafío. Buenos Aires: Editora Legasa S.A, 1992, p. 75109. 
. Tres factores en la reestructuración hemisférica. In: ROJAS ARAVENA, Francisco; SMITH, William C. (Edit.). El Cono Sur y las transformaciones globales. Santiago de Chile: CLADDE, FLACSO, North South Center, 1994, p. 239-254.

LERMAN ALPERSTIEN, Aida. La agonía del MERCOSUR. Comercio Exterior, México, v. 55, n. 4, p. 362-375, abril. 2005.

MALAMUD, Andrés. A neighborhood policy for South America? Some critical notes. São Paulo: Specialist Paper, OBREAL EURALO, September. 2006.

- MERCOSUR turns 15: between rising rhetoric and declining achievements. Cambridge Journal of International Affairs, v. 18, n. 3, p. 421436, October. 2005,.

MEDEIROS, Marcelo de Almeida. La genèse du MERCOSUD. Paris: L'Harmattan, 2000.

RODRÍGUEZ, José Carlos. Una ecuación irresuelta: Paraguay-MERCOSUR. In: DE SIERRA, Gerónimo (Comp.). Los rostros del MERCOSUR. El difícil camino de lo comercial a lo societal. Buenos Aires: CLACSO, 2001, p. 361-372.

SCHMITTER, Philippe. A revised theory of regional integration. International Organization, n. 24, p. 836-865, autumn. 1970.

SMITH, Peter. The politics of integration: concepts and themes. In: SMITH, Peter. (Ed.). The challenge of integration: Europe and the Americas. New Brunswick: Transaction Publishers, 1993, p. 1-14.

STAHRINGER, Ofelia. Los acuerdos de integración Argentina-Brasil, Argentina -Chile en el marco del MERCOSUR y de un nuevo relacionamiento con Estados Unidos. In: LAREDO, Iris Mabel (Comp.). La integración latinoamericana en el actual escenario mundial: de la ALALC-ALADI al MERCOSUR. Rosario: Facultad de Ciencias Políticas y Relaciones Internacionales, Universidad Nacional de Rosario, 1992, p. 53-74. 
SUKUP, Victor. MERCOSUR, Unión Europea y 'modelos' económicos: perspectivas de una nueva inserción internacional. In: BERNAL-MEZA, Raul; KUMAR SAHA, Suranit (Edit.). Economía mundial y desarrollo regional. Buenos Aires: Nuevohacer Grupo Editor Latinoamericano, 2005, p. 187-217.

VAN KLAVEREN, Alberto. Las nuevas formas de concertación política en América Latina. In: MUÑOZ VALENZUELA, Heraldo; ORREGO VICUÑA, Francisco (Edit.). La cooperación regional en América Latina. Santiago: El Colegio de México-Universidad de Chile, 1986, p. 503-528.

VAZQUEZ, Mariana. Hacia una integración estratégica en el Cono Sur. MERCOSUR: ¿Potencial y/o realidad? In: SOLANAS, Fernando; VÁZQUEZ, Mariana. MERCOSUR: Estado, economía, comunicación y cultura. Buenos Aires: Eudeba, Facultad de Ciencias Sociales, Universidad de Buenos Aires, 1998. 